\title{
REFLECTION OF THE IDEA OF CONSERVATION OF THE INTANGIBLE HERITAGE IN THE PROCESSES OF EVOLUTION OF CHROMATIC KEYPADS OF THE HARMONICS
}

\author{
Nikolay Kravtsov \\ kravtsov@accordionkravtsov.ru
}

Saint Petersburg State University of Culture, Russia

\begin{abstract}
The main lines of the evolutionary development of harmonics keyboards are revealed. The varieties of diatonic and chromatic harmonics during their historical formation in the period from 1829 to the present. Disclosed artistic and performance properties of instruments, most effectively meeting the needs of various genres of intangible musical heritage.

The principles of the relationship between improvements in tool design and modern genres, ensuring the preservation and growth of folk and academic traditions. New expressive properties of modern harmonics providing sustainable perspectives for tools in processes preservation of intangible heritage.

Keywords: Evolution; Diatonic Keyboards; Chromatic Keyboards; Artistic and Expressive Properties of Harmonics; Intangible Heritage; Traditional Musical Genres; Life of Instruments; Push-button Accordions; Keyboard Accordions; Kravtsov System Accordions.
\end{abstract}

\section{ОТРАЖЕНИЕ ИАЕИ СОХРАНЕНИЯ НЕМАТЕРИААЬНОГО НАСАЕАИЯ В ПРОЦЕССАХ ЭВОАЮЦИИ ХРОМАТИЧЕСКИХ КААВИАТУР ГАРМОНИК 1}

\author{
Николай Кравцов \\ Санкт-Петербургский государственный институт культуры, Россия
}

Резюме: Выявлены основные Аинии эволюционного развития к^авиатур гармоник. Показаны разновидности Аиатонических и хроматических гармоник в ходе их исторического фрормирования в периол с 1829 гола по настоящее время. Раскрыты художественноисполнительские свойства инструментов, наиболее эфффективно отвечающих запросам различных жанров нематериального музыкального наследия. Освещены принципы взаимосвязи усовершенствования конструкции инструментов с современными

В статье публикуются результаты Аоклала, представленного на конореренции $\mathrm{LCH} 2019$ 
жанрами, обеспе-чивающие сохранение и преумножение народных и акалемических традиций. Изучены новые выразительные свойства современных гармоник, обеспечивающих устойчивые перспективы инструментам в процессах сохранения нематериального наследия.

КАючевые слова: эволюция; клавиатуры Аиатонические; хроматические клавиатуры; художественно-выразительные свойства гармоник; нематериальное наследие; тралиционные музыкальные жанры; бытование инструментов; кнопочные аккордеоны; клавишные аккордеоны; аккордеоны системы Кравцова

В настоящем исследовании автор обращается к сорере малоизученной области музыкознания - взаимосвязи бытования тралиционной музыки и формирования её многочисленного инструментария - гармоник. Зародившиеся в 19-м столетии гармоники изначально стали развиваться по Авум Аиниям.

Первая миния илёт от изобретения австрийцем К. Аемианом аккорлеона, а вторая - от созАания английским физиком Ч. Уитстоном концертино. Почти Авести ^ет прошло с момента созАания австрийцем армянского происхожАения Киримлом Аемианом (Ciyrill Demian) механизма Аля новой клавиатуры гармоники (6 мая 1829 г.), которая обеспечила инструменту Аолгожительство в мировой музыке. Это изобретение, пусть и на простейшем уровне, оказалось способным ответить бытовым запросам как ^юлей эпохи Аиександра Пушкина, роберта Шумана, Фредерика Шопена, Михаила Глинки, Гектора Берлиоза, Александра Аюма так и нашим современникам. Не многие изобретения могут так Аолго быть полезными. Ааже паровозы не прожили Аольше и практически мы их виАим только в кино и музеях. Гениальность илеи К. Аемиана практически не имела аналогов - он обеспечи^ нажатием одной кнопки звучание целого аккорда, что упрощало игру.

При офрормлении Аокументов на приоритет изготовления к^авиатуры, он назвал инструмент «аккорАеоном». Поэтому все инструменты с его системной илеей так и называются - аккорАеон (das Akkordion - немецкий, accordion - английский). При появлении аккордеонов в России и Италии они получили при переводе на русский язык - гармоника (в быту гармонь, гармошка), а на итальянский - Іа fisarmonika (Lips, 2007), (Mirek, 1967), (Puchnowski, 1964), (Yastrebov, 1976), (Zilbertquit, 1973), (Zimin, 1968). 
A Аальше у аккордеона Аемиана началась Аолгая и счастливая жизнь. Его современный ариал распространения прохолит по всем континентам. Его голос звучит во всех жанрах мировой музыки. Если сравнить современные аккорАеоны с прототипом К.Аемиана, то внешне они очень отличаются. ОАнако их генетическое родство сразу же обнаруживается в звучании аккордов левой клавиатуры современных инструментов. Их роднит также специфическое в тембральной и Аинамической окраске звукообразование, которое осуществляется при помощи проскакивающих металлических язычков.

После того как в сознании музыкантов утверАилось позитивное отношение к ритмо-гармоническому аккомпанементу аккорлеона, стало очевиАно, что инструмент можно совершенствовать Аальше путём созАания Аополнительной мелоАической кАавиатуры. Поэтому к^авиатура К. Аемиана бы^а перенесена в левый полукорпус (как виАно по сохранившимся материалам заявленная клавиатура К. Аемиана находилась со стороны правой руки). С этого момента начались поиски по созАанию клавиатур Аля правого полукорпуса. Эти работы проходили непосредственно на фоне смены различных музыкальных эпох и стилей 19-21 веков и в конечном итоге быстро интегрировались в эволюционные процессы мировой музыки и в первую очередь народную (Belyavsky, 1925), (Helmholtz, 1975).

В 19-м столетии, поА Аавлением меняющихся запросов музыкального общества, этот периол отмечен попытками преобразовать традиционную клавиатуру рояля. Напомним схематично основные этапы эволюции органно-фрортепианной клавиатуры. Упоминания о к^авиатуре уходят глубоко в историческое прошлое. Основные этапы раннего периола формирования клавиатуры наполнены рялом существенных преобразований.

Во-первых, с усовершенствованием гинропневматической механики гиАравлоса ${ }^{2}$ появи^ась возможность заменить его выАвижные к^авиши более удобными Аля игры - нажимными (I век АО Н.э., Витрувий). ВыАвижные к^авиши гиАрав^оса уже в первом веке $о$ нашей эры показали свою неспособность ответить музыкально-стилистическим

2 ГиАравлос - воляной орган, в камере которого постоянное давление возАуха обеспечивалось гиАравлическим устройством. Изобретен в III в. АО Н.э. механиком Ктезибием 
изменениям музыкальной культуры. Игра на вылвижных клавишах вынужАала к АвУм Авижениям: захват и вылвижение рычага. При развитых метро-ритмических фрункциях такие затруднительные Аействия рожАали всё большие неулобства. Перехол к нажимным клавишам сокращал игровые Авижения наполовину. Спустя несколько столетий наряду с нажимными выАвижные кАавиши были повторены в разных конструкциях переносных органов - портативов (Portatif). В Аальнейшем всеобщее применение получила конструкция нажимных клавиш (Savshinsky, 1961), (Sherman, 1964).

Во-вторых, в зависимости от способа звукообразования инструмента рожАались различные размеры клавиш и игровых п^ощаАок. Вспомним про: крупные клавиши - рычаги Аиатонических органов, маленькие, почти квалратные клавиши клавикорлов, которые были уАобны Аля игры четырьмя пальцами, и уАобными А^я получения звуковысотной вибрации (Bebung), про уАлинённые клавиши у фортепиано, позволяющими горизонтально-скользящее Авижение пальцев и обеспечивающие эргономическую алаптацию различных по анатомическим строениям рук. В процессе эволюции установившиеся размеры игровых площадок чёрных и белых клавиш следует рассматривать как определённый этап приспособления конструкций к строению руки и к способу игры пятью пальцами в условиях фортепиано.

В-третьих, перехол от пифрагорейского строя к неравномерно темперированному и равномерно-темперированному строям ознаменовался увеличением количества клавиш в олной октаве от восьми $\triangle о$ АвенаАцати.

В-четвёртых, постоянная тенденция увеличения звукового Аиапазона инструментов влекла за собой увеличение общего числа к^авиш во всей клавиатуре.

В-пятых, как в научно - познавательных, так и в экспериментально-исполнительских целях созАавались инструменты, клавиатуры которых имеАи в оАной октаве свыше АвенаАцати кАавиш (напр. гармониум Эйтца с 52 клавишами и 104 звуками в оАной октаве). На развитие гармоник оказали прямое воздействие третий и четвёртый этап орормирования рояльной клавиатуры.

А мальше гармоника откликалась на все появляющиеся преобразования в конструкции органно-фортепианной клавиатуры. С 
активным использованием композиторами 19 столетия целотонной гаммы, среди которых в первую очередь вылеляются К. Аебюсси и Н.А. Римский-Корсаков, Пауль Янко созАаёт состоящую из Авух ряАОв КАавиш к^авиатуру А^я фортепиано [Фиг. 1],. В кажАОМ из ряАов кАавиши ОН разместил в последовательности целого тона. Несколько позАнее клавиатура была улучшена Франке и Блютнером (1887).

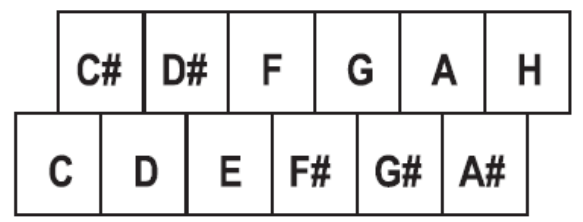

\section{Фиг.1. Схема тонов октавы на клавиатуре Пауля Янко}

В колмекции Санкт-Петербургского музея музыкальных инструментов имеются пианино с шестирядной кАавиатурной системой П. Янко, в которой $А$ ва основных и четыре послеАовательно Аублирующих ряла предоставляют исполнителю Аополнительные возможности в аппликатурных решениях. На этой кАавиатуре пианист может применить абсолютно олинаковую аппликатуру во всех тональностях. Были изготовлены и гармоники с клавиатурой П. Янко [Фиг. 2].

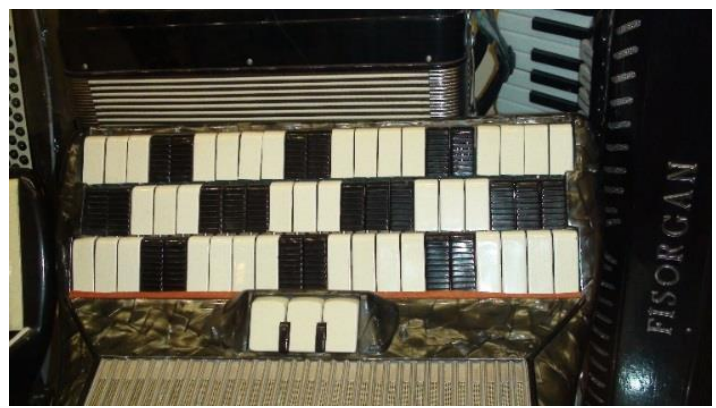

Фиг. 2. Итальянский аккордеон (1927 г.) с кАавиатурой системы П.Янко с Аублирующим третьим ряАом, гАе к^авиши выполнены в УАлинённой форме 


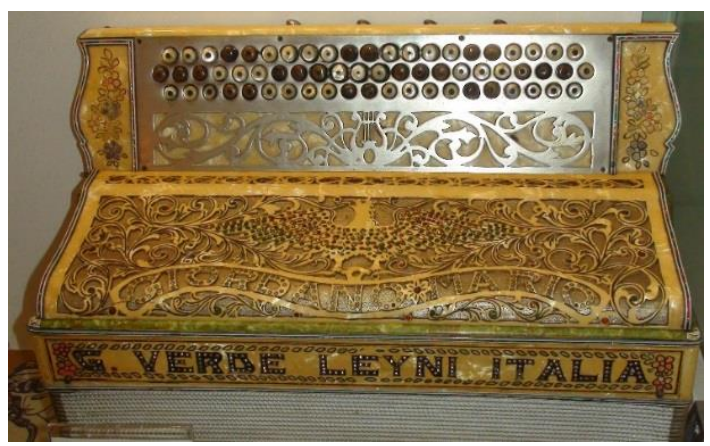

Фиг.3. Аккораеон с клавиатурой системы П.Янко (изготовлен в 1927 г.),

\section{в которой кАавиши выполнены в форме кнопок}

Оценивая френомен клавиатуры П. Янко [Фиг. 3], следует заметить, что она всё же не прижилась в музыкальной практике. При всех положительных свойствах она имела, как всякое устройство, ряА неАостатков, которые оказались решающими в её интеграции в музыкальную культуру гармоник. По мнению игравшего на ней ^енинградского баяниста А.З. Кудрявцева, техника игры аккорАов и скачков на клавиатуре монофона была затруднительной. Наиболее определённое и меткое замечание приналлежит советскому пианисту и педагогу С.И. Савшинскому, который считал, чтобы играть на к^авиатуре Янко пианисту наАо переучивать, а не Аоучиваться. Фактически Пауль Янко преАложил революционный путь в развитии клавиатуры рояля и поэтому в консервативной музыкальной культуре, невзирая на усилия энтузиастов илеи, этот проект потерпел фриаско.

В сорере сохранения нематериальных тралиций, как России, так и Болгарии, такой инструмент не появлялся - А^я этого не бы^о необходимых предпосылок. Ао появления клавиатуры Янко в Европе Аоминировала Аиния Аиатонических гармоник (Франция, Германия, Россия, Австрия, Италия, Гомландия). В Болгарии следы миатонических гармоник прослеживаются слабо. По мнению автора это связано с хроматической орнаментикой, характерной Аля болгарской тралиционной музыке, гАе Аоминирует малая секунАа.

Извлечь её из Аиатонического инструмента бы^о невозможно. Кроме того, в традиционном болгарском вокальном жанре "а cappella» Аоминирова^ не темперированный строй, что также не способствовало широкому распространению Аиатонических 
инструментов, гАе повсеместно были распространены не темперированные инструменты - кова^ и галулка.

С момента заимствования в конструкцию аккорАеона К.Аемиана хроматической клавиатуры рояля начинается новый этап распространения инструмента, связанный с попытками апробировать новый инструмент в различных орормах музыкальной культуры. На Фиг. 4 изображён олин из первых аккорАеонов с органно-фортепианной клавиатурой. Он Аатируется 1852 годом и бы^ привилегией обеспеченных слоёв населения.
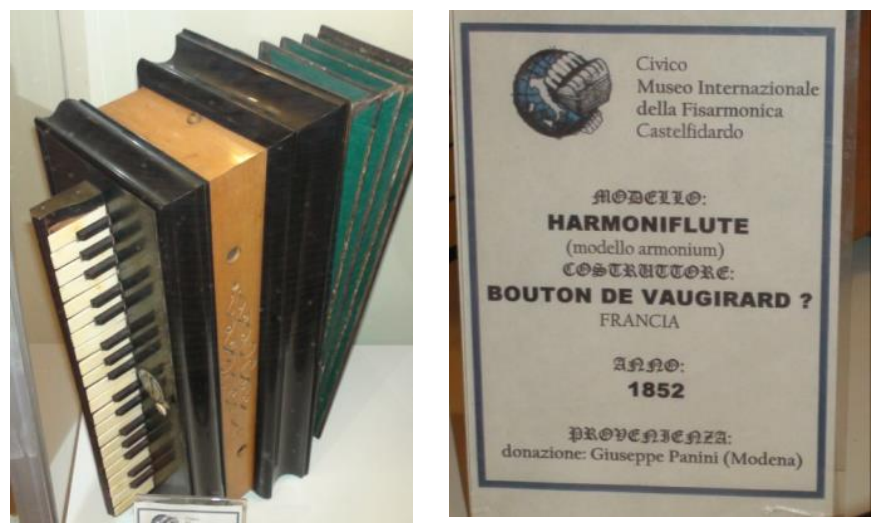

Фиг. 4. Гармоника произвоАства 1852 гоАа, Франция;

находится в музее гармоник города КастельфидарАо (Италия)

Современный виА хроматического клавишного и кнопочного аккордеона сорормировался с созданием системы размещения кнопок-аккорАов типа "Stradella". В 20-м столетии инструмент с кАавишной кАавиатурой рояля нача^ быстро распространяться во многих странах мира, в том числе в Болгарии и в республиках СССР.

В тралиционной болгарской музыке сегоння ОН заня^ Аоминирующую позицию в танцевальной музыке почти по всей территории страны. Сорормировавшийся тип аккорлеона успешно справлялся с функцией сопровожАающего танцы инструмента. Сохраняя тралиции нематериальной болгарской музыки, он постепенно заня^ ^идирующее место в жанре. В традиционной музыке народов СССР в прошеАшем веке он распространился парал^ельно с кнопочными Аиатоническими и хроматическими гармониками. 
Вторая миния гармоник велёт своё начало практически одновременно с созданием К. Аемианом аккордеона. Она появилась Авумя неделями позАнее в том же 1829 голу. Инструмент, который созАал знаменитый английский учёный Чарлз Уитстон (патент, ^онАОН, 1829), отличался тем, что в его правой и левой клавиатурах были только мелодические звуки. Эти инструменты детально описаны фрранцузским композитором Гектором Берлиозом в труде «Большой трактат о современной инструментовке и оркестровке...», в котором крупнейший музыкант 19 века предполагал использовать их как оркестровые инструменты (Berlioz, 1972). Эта миния продолжалась с созАанием Генрихом БанАом бандонеона с изменённым размещением кнопок в правом и левом полукорпусах инструмента. Конечная орорма инструмента Ч. Уитстона - аккордеоны с мелодическими клавиатурами. У этих инструментов в обоих полукорпусах размещались известные системы хроматических клавиатур - «B-Griff», «C-Griff» и органнофортепианная. Они были предназначены для веления соборных служб там, гАе отсутствова^ орган или портатив.

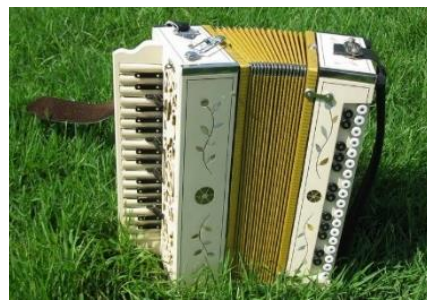

\section{Фиг. 5. Аккораеон с мелодическими голосами, гАе в левом полукорпусе клавиши органно-фортепианной к^авиатуры выполнены в форме кнопок}

После клавиатуры Пауля Янко, которая имела в рялах размещение клавиш в интервале целого тона, музыкальный мир клавишных инструментов замер в ожиАании появления к^авиатур с ряАами клавиШ в интервале полутора тона или малой терции. Оптимизма современникам Аобавляли сочинения Н.А. Римского-Корсакова, К.Аебюсси и Аругих композиторов, гАе была использована целотоная гамма. СлеАует обратить внимание на тот фокт, что в истории аккорАеона к^авиатура П. Янко яви^ась как бы стыковочным элементом - ореноменом, родоначальником, предтечей кнопочных хроматических клавиатур. Но у хроматических кнопочных к^авиатур была ещё олна «ролная мама» - Аиатоническая 
к^авиатура гармоник, повсеместно распространившихся в XIX веке на территориях разных стран Европы, вкАючая Россию. В процессе бытования Аиатонические гармоники расширили свой Аиапазон и, чтобы сохранить старые габариты инструментов, мастера укоротили клавиши олного ряда через олну. Прикрепив к краям кАавиш кнопки, получилось Ава ряла знакомых всем композиция. В рядах они располагались в различной последовательности интервалов малых и больших терций, Поэтому музыканты и мастера легко учли особенности Авух конструкторских иАей и применили их вместе в оАном инструменте - хроматической кнопочной гармонике, имеющей в рядах кАавиш интерва^ терции, но только оАной - малой. Эта конструктивная нахоАка связала цепочку развития клавиатурных систем органно-фортепианной и кнопочных к^авиатур в мировой музыкальной культуре. Устройства новых кнопочных клавиатур с михвой помогАо реализовать исполнительские амбиции гармонистов и открыли необычные возможности в музыкальном языке А^я кАавишных инструментов (Matsievsky, 2007).

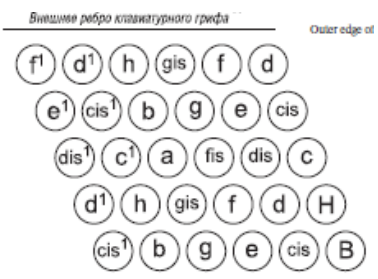

\section{Фиг. 6. В-Griff и его разновиАности}

На рубеже 19 и 20 столетий сфоормировались практически все современные кнопочные клавиатуры [Фиг 6, 8 и 10].
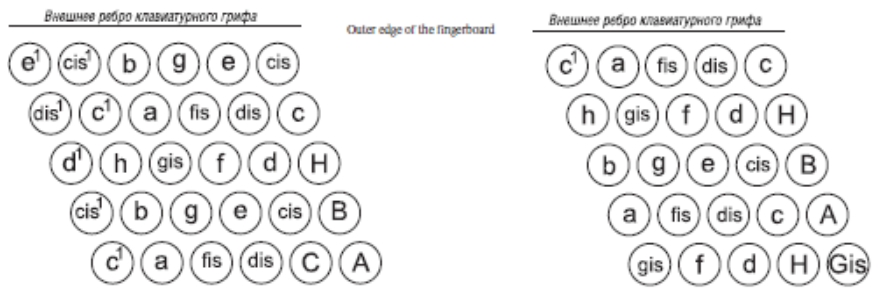

Фиг. 7. В-Grif Бельгийская система(Charleroi) Брюссельская система 


$$
\begin{aligned}
& \text { (dis (c) (a) fis (dis) (c) } \\
& \text { (cis } \text { (b) (g) (cis) B } \\
& \text { (h) gis (f) (d) (His) } \\
& \text { (a) fis dis (C) A Fis } \\
& \text { (g) (e) (B) (E) }
\end{aligned}
$$

Фиг. 8. С-Griff и его разновианости
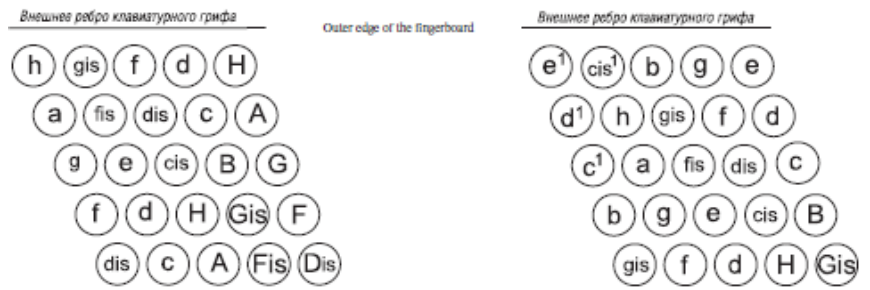

Фиг. 9. ШвеАско-итальянская система Финская систем

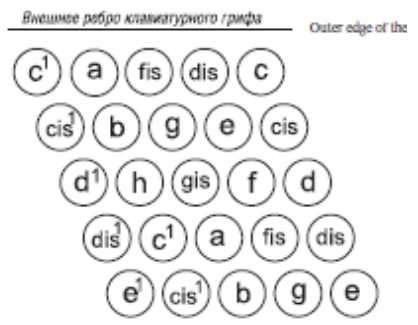

Фиг. 10. Французская система
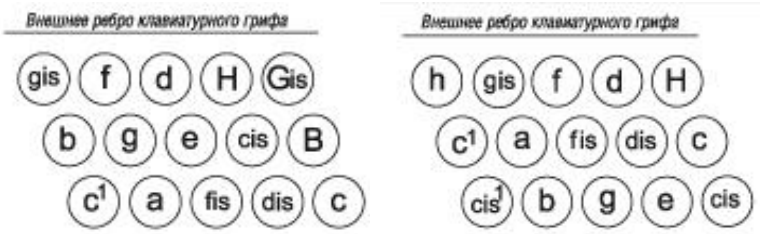

Фиг. 11. Система П. Е. Стерлигова

Фиг. 12. Система Н. 3. Синицкого 


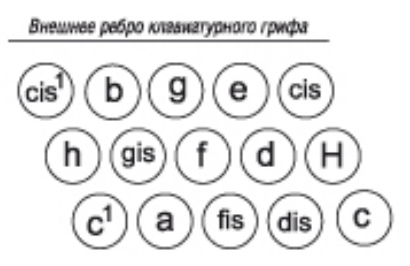

\section{Фиг. 13. Система В. П. Хегстрема}

^юбопытен фоакт, что к настоящему времени прекратили существование, созАанные российскими мастерами, три хроматические кнопочные клавиатуры - П. Е. Стерлигова [Фиг. 11], Н.3.Синицкого [фиг. 12] и В. П. Хегстрема [Фиг. 13].

Сеголня остаётся А^я музыкантов нерешённым вопрос: какая система наиболее перспективна м^я аккордеона? Похоже, что проблема не решится в ближайшее время. Сильнейшим конструктивным отличием всех систем кнопочных кАавиатур является их, более компактное, чем у рояльной, размещение в октаве клавиш 12-ти ступеней равномерно-темперированного строя.

Это конструктивное решение откры^о новые художественновыразительные свойства в оригинальном репертуаре и позволило озвучить ранее недоступные звуковые возможности в сохранении нематериального наследия у многих народов. И всё это - благодаря широкому разнесению голосов в музыкальных фрактурах.

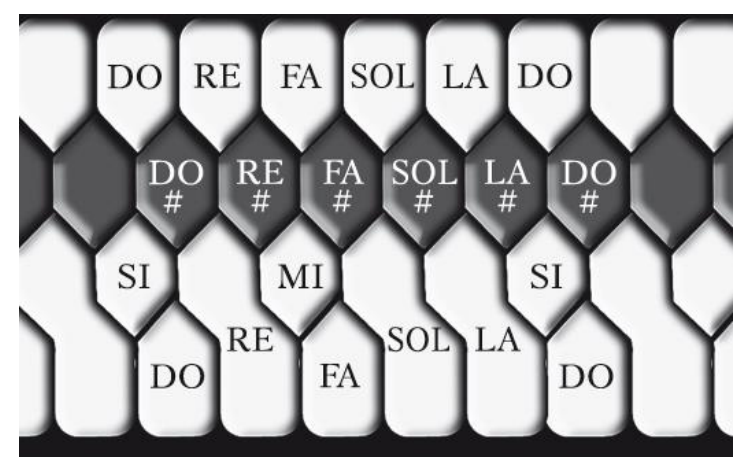

Фиг. 14. Схема размещения к^авиш на правой к^авиатуре по системе Кравцова 
ОАновременно с этим стало очевиАно, что заимствованная в гармонику органно-фортепианная к^авиатура не может ответить современным тенденциям молодой инструментальной культуры. Автор преАложи^ алаптировать в соответствии с запросами современности конструкцию популярной рояльной кАавиатуры, и уменьшил площаАь размещения клавиш её тралиционной октавы на 38 \%.

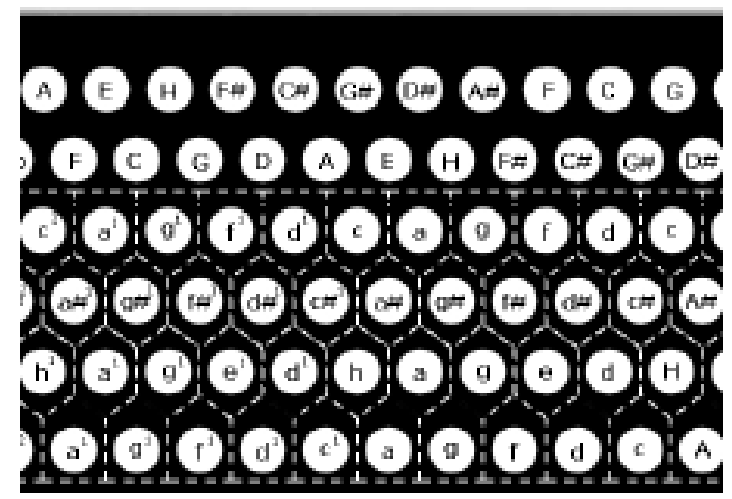

Фиг. 15. Схема размещения кнопок на левой выборной клавиатуре по системе Кравцова

Кратко преимущество аккордеона системы Кравцова [Фиг. 14, 15] можно изложить в слеАующих положениях:

1. Сохраняя навыки игры на органно-орортепианной клавиатуре аккордеона, музыкант может исполнить, не искажая авторский текст Аюбого оригинального произведения, быть совершенно творчески своболным в выборе новых художественно-выразительных среАств при реализации нематериального традиционного наследия в музыкальном творчестве;

2. Упрощает существующий процесс обучения игре на аккорлеоне;

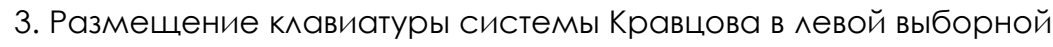
конструкции позволило сократить изучение аккорАеонистом к^авиатурных устройств $А$ 2-х вместо существующих в аккорАеоне 3-х.

В Авалцатом веке музыканты и мастера стали искать пути объеАинения в одном инструменте илеи К.Аемиана и Ч.Уитстона. В результате появился концертный инструмент, гАе в ^евом полукорпусе система аккордов Stradella могла переключаться на мелодическую хроматическую. Такая клавиатура получила название в СССР «готово-

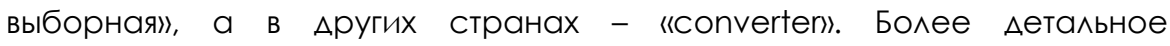


рассмотрение этого важного процесса формирования нового типа к^авиатуры не позволяет объём настоящего сообщения (Kravtsov, 1982), (Kravtsov, 2004), (Kravtsov, 2012).

Важно А^я нас, что эта конструкция выводит на новый уровень воспроизведения образцы нематериального наследия музыкального традиционного искусства. Учитывая вышеизложенное, можно слелать следующие выводы:

1. Наличие в практике музыкальной культуры семи кнопочных к^авиатур и Авух к^авишных свидетельствует, что процесс криста^^изации конструкций А^я кАавишных инструментов не закончен.

2. В то же время органно-орортепианная клавиатура остаётся базовой в музыкально-эстетическом воспитании, в тралиционных и массовых жанрах музыкальной культуры (фролк, Ажаз, рок, кроссовер и Т.п.)

3. Вместе с тем, определились основные преимущества компактных кнопочных к^авиатур и к^авишной системы Кравцова, как возможных носителей нового музыкального языка в инструментальной культуре.

4. Эти клавиатуры обладают богатейшим потенциалом нераскрытых художественно-выразительных средств, которые могут быть с успехом использованы как в создании оригинальных сочинений, так и в сохранении нематериального наследия народов мира.

\section{Аитература / References}

Belyavsky, A. G. (1925). Theory of sound as applied to music: Fundamentals of physical and musical acoustics. - M .; L .: GIZ, 1925, - 239 р. (In Russian) / [Белявский А. Г. Теория звука в приложении к музыке: Основы фризической и музыкальной акустики. - М.; А.: ГИЗ, 1925, - 239 с.]

Berlioz, G. (1972). A large treatise on modern instrumentation and orchestration, containing: accurate information on the volume of various instruments, a brief description of their devices and a characteristic of their timbre and expressive features, accompanied by a large number of musical examples taken from the works of the Greatest Masters and some unpublished works of the author / C add. R. Strauss; Per., Ed. entry article and comment. S.P. Gorchakova, - M. Music, 1972 (In Russian) / [Берлиоз Г. Большой трактат о современной инструментовке и оркестровке, солержащий: точные свеления об объёме различных инструментов, краткое описание их устройств и характеристику их тембра и выразительных особенностей, сопровожАаемый большим количеством партитурных примеров, взятых из произведений Величайших Мастеров и некоторых неопубликованных сочинений автора / C Аоп. Р.Штрауса; Пер., реА. вступ. статья и коммент. С.П.Горчакова, - М. Музыка, 1972] 
Helmholtz, G. (1975). The doctrine of auditory sensations as a physiological basis for the theory of music. - St. Petersburg, 1875 (In Russian) / [Гельмгольц Г. Учение о слуховых ощущениях как фризиологическая основа Аля теории музыки. - СПб., 1875]

Kravtsov N. A. (1982). Improvement of the organ-piano keyboard of the accordion and the pressing problems of harmonious accordion performance: PhD thesis: 17.00.02 / Kravtsov Nikolay Alexandrovich; [LGITMiK]. - L., 1982 (In Russian) / [Кравцов H.A. Усовершенствование органно-фрортепианной клавиатуры аккорлеона и назревшие проблемы гармонно-баянного исполнительства: Аис. канА. искусствоведения: 17.00.02 / Кравцов Николай Александрович; [^ГИТМиК]. - ^., 1982]

Kravtsov N. A. (2004). 21 st Century Accordion / N. A. Kravtsov. - St. Petersburg: Publishing House "MTT", 2004 (In Russian) / [Кравцов Н.А. Аккордеон XXI века / Н. А. Кравцов. СПб.: ИзАательство «МСТ», 2004]

Kravtsov N. A. (2012). Tables of fingering scales, chords and arpeggios for ready-made accordion: textbook. Manual / NA Kravtsov; Culture of the Russian Federation, St. Petersburg. state University of Culture and Arts, fac. Arts nar.tools; Photographer. work of S. Algin. - SPb. : Publishing house of SPbGUKI, 2012 (In Russian) / [Кравцов Н.А. Таблицы аппликатур гамм, аккорлов и арпеджио Аля готово-выборного аккордеона : учеб. пособие / Н. А. Кравцов ; М-во культуры Рф, С.-Петерб. гос. ун-т культуры и искусств, фрак. искусств, каф. нар.инструментов; нотографр. работы С. Альгина. - СПб. : ИзА-во СПбГУКИ, 2012]

Lips F. (2007). On the art of button accordion transcription: Theory and practice. - M. 2007: Music, - 136 s. (In Russian) / [^ипс Ф. Об искусстве баянной транскрипции: Теория и практика. - М. 2007: Музыка, - 136с., нот]

Matsievsky I. (2007). Folk instrumental music as a cultural phenomenon. - Almaty: Dyke Press. 2007 (In Russian) / [Мациевский И. Народная инструментальная музыка как френомен культуры. - Амматы: Аайк-Пресс.2007]

Mirek A. M. (1967). From the history of accordion and button accordion. - M.: Music, 1967 (In Russian) / [Мирек А.М. Из истории аккордеона и баяна. - М.: Музыка, 1967]

Puchnowski W. (1964). Szkole miechowania I artikulacji akordeonowej. - Krakow, PWM, 1964

Savshinsky S. I. (1961). The pianist and his work. - L .: Soviet composer, 1961 (In Russian) / [Савшинский С.И. Пианист и его работа. - ^.: Сов. композитор, 1961]

Sherman N. (1964). Formation of a uniformly-tempered system. - M.: Music, 1964 (In Russian) / [Шерман Н. Формирование равномерно-темперированного строя. М.:Музыка, 1964]

Yastrebov Yu. (1976). Modern principles of button accordion fingering. Thesis of doctor at art history (DSC). - L., 1976 (In Russian) / [Ястребов Ю. Современные принципы баянной аппликатуры : Автореор. Аис. на соиск. учён. степ. канА. искусствоведения. - ^., 1976]

Zilbertquit M. (1973). Birth of the piano. - M.: Sov. Composer, 1973 (In Russian) / [Зильбертквит М. РожАение фортепиано. - М. : Сов. Композитор, 1973]

Zimin P. N. (1968). The history of the piano and its predecessors. - M.: Music, 1968 (In Russian) / [Зимин П.Н. История фрортепьяно и его предшественников. - М.: Музыка, 1968] 


\section{КУАТУРНО-ИСТОРИЧЕСКО НАСАЕАСТВО: \\ ОПАЗВАНЕ, ПРЕАСТАВЯНЕ, АИГИТААИЗАЦИЯ}

\section{CULTURAL AND \\ HISTORICAL \\ HERITAGE}

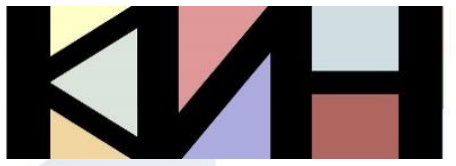

PRESERVATION PRESENTATION DIGITIZATION

\section{Съставители \\ Галина БогАанова Ваня Матеева}

Материалите в сборника са обект на авторско право. Разрешава се безвъзмезАното ползване на техни електронни/ хартиени копия само за лична употреба или обучение, при пьлно цитиране на текущата страница и слеА писмена Аекларация от цитиращия за Аипса на тьрговски намерения. За копиране поА Аруга фрорма, препубликуване или публикуване на сървьри се изисква писмено разрешение и/или заплащане.

() Авторски колектив, 2019 Технически реАактори: Николай Ноев Калина Сотирова-Вълкова Ка^оян Николов

\section{Editors}

Galina Bogdanova Vanya Mateeva

This work is subject to copyright. Open and free of charge use of digital/hard copies of publications is granted only for personal or educational use, with full citation of the current page, and after written declaration of the quoting side for not-commercial Intention. For any other reproducing types, republishing, photocopying, recording, or any other storage retrieval system/ server written permission and/or fee is required.

() Authors` Group, 2019

Technical editors:

Nikolay Noev

Kalina Sotirova-Valkova

Kaloyan Nikolov

\section{Научна поредица: том 5, брой 2 (7)/2019}

Science series: vol. 5 , issue $2(7) / 2019$

www.math.bas.bg/vt/kin

ISSN: 2367-8038 